\title{
A REVIEW OF RAMAN, SURFACE-ENHANCED RAMAN SCATTERING (SERS) AND RELATED SPECTROSCOPIC TECHNIQUES APPLIED TO BIOMOLECULES IN BIOMATERIALS
}

\author{
FREDDY CELIS ${ }^{*}, 2$, MACARENA GARCIA ${ }^{3}$, GUILLERMO DIAZ-FLEMING ${ }^{4}$ AND \\ MARCELO CAMPOS-VALLETTE ${ }^{2}$ \\ ${ }^{I}$ Laboratorio de Espectroscopía Vibracional Aplicada, Departamento de Química y Centro de Estudios Avanzados (CEA), \\ Universidad de Playa Ancha, Valparaiso, Chile. \\ ${ }^{2}$ Laboratorio de Espectroscopía Vibracional, Departamento de Química, Universidad de Chile, Santiago, Chile. \\ ${ }^{3}$ Laboratorio de Polímeros Conductores, Departamento de Química de los Materiales, Facultad de Química y Biología, \\ Universidad de Santiago de Chile, Santiago, Chile. \\ ${ }^{4}$ Laboratorio de Espectroscopía Atómica y Molecular, CESPAM, Departamento de Química, Universidad de Playa Ancha, Valparaíso, Chile.
}

\section{ABSTRACT}

The development of new biomaterials has gained increasing attention in the last decade. One of the most important aspects in the development of these new materials is to understand the chemical cues presents in the native niche. Among all the techniques currently available for measuring those interactions, Raman spectroscopy offers a unique and non-invasive tool for exploring the behavior of the components within a given biomaterial and their surrounding microenvironment. This technique exploits the unique molecular vibrational fingerprints for pinpointing those interactions. The vibrational response can be improved to the single molecule level, in the presence of metal nanoparticles (NPs) with plasmonic properties (silver, gold and copper) in the so-called SurfaceEnhanced Raman Scattering (SERS), which can be used for in-situ measurements. Another technique recently developed is the Shell-Isolated NanoparticleEnhanced Raman Spectroscopy (SHINERS), which overcomes signal contamination from chemical interactions between biomolecules and the metal surface; it does this by coating the metal surface with an inert layer of alumina or silica. In the present contribution, the role and the applications of Raman, SERS and related spectroscopic techniques in the study of biomolecules in biomaterials are reviewed and discussed.

Keywords: Raman, SERS, Biomolecules, Biomaterials, Nanoparticles.

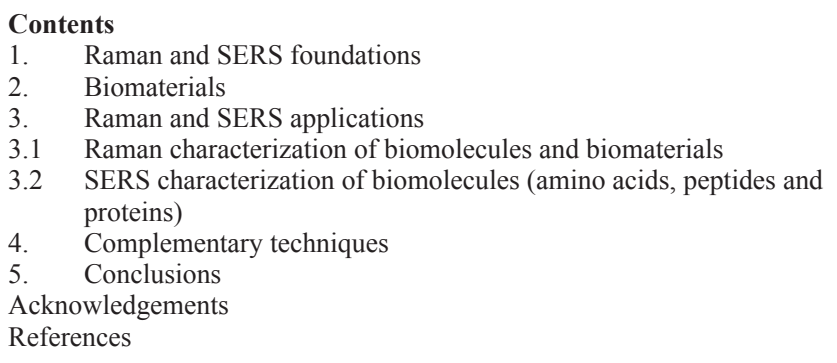

1. Raman and SERS foundations.

The Raman effect was first described in 1928 by Sir Chandrasekhara Venkata Raman ${ }^{1}$, being the development of this technique relevant when the laser sources became available in the 1960s. The uses for Raman spectroscopy is intrinsically limited by the weak signal generated from the inelastic light scattered by a molecule (Scheme 1a). For example, the cross-section light scatter for benzene is $2.8 \times 10^{-29} \mathrm{~cm}^{2}$ molecule ${ }^{-12}$. The efficiency can be enhanced through the SERS technique ${ }^{3,4}$, where the Raman spectral enhancement arises from a roughened surface of a metal with plasmonic properties (Scheme 2). The most SERS-active metals are Ag, $\mathrm{Au}$ and $\mathrm{Cu}$. The first enhanced-Raman spectrum was observed by Fleischmann ${ }^{4}$; in this experiment, pyridine was adsorbed on a silver surface electrochemically treated by continuous oxidationreduction cycles. The effect is based on the enhancement of the inelastic scattering from molecules close to nanoparticles (Scheme 1b); the enhancement is in the range of $10^{5}-10^{6}$ order of magnitude (cross sections of $10^{-17}-10^{-16}$ $\mathrm{cm}^{2}$ molecule ${ }^{-1}$. An important consideration when using metal nanoparticles is the surface charge. Recently, Garrido et al ${ }^{5}$ developed new silver nanoparticles to obtain a SERS signal of negatively charged bio-analytes thus improving the uses of the SERS technique. Other SERS substrates were developed by GarciaLeis and Stamplecoskie ${ }^{6,7}$. General methodologies to obtain nanoparticles were reported and widely used ${ }^{8,10}$. In this field, an important book about AgNPs, (the most widely used metal nanoparticles), was recently published ${ }^{11}$, where several topics in the AgNPs field such as new synthetic routes, nanoparticles for catalysis mediated by plasmon, biomedical uses and anti-microbiological and anti-infective activities of nanoparticles are discussed.

Technological advances have enable Raman spectroscopy branch out in a number of different fields of general science. It is possible to find applications using Raman spectroscopy for instance in the field of space science ${ }^{12,13}$, pharmaceutical drugs ${ }^{14-19}$, oceanography ${ }^{20}$, detection of pesticides
${ }^{21-23}$, forensic science ${ }^{24}$ and heritage studies ${ }^{25}$. The use of Raman and SERS spectroscopy in the study of biomaterials was reported in books and articles in the last years ${ }^{26-31}$.

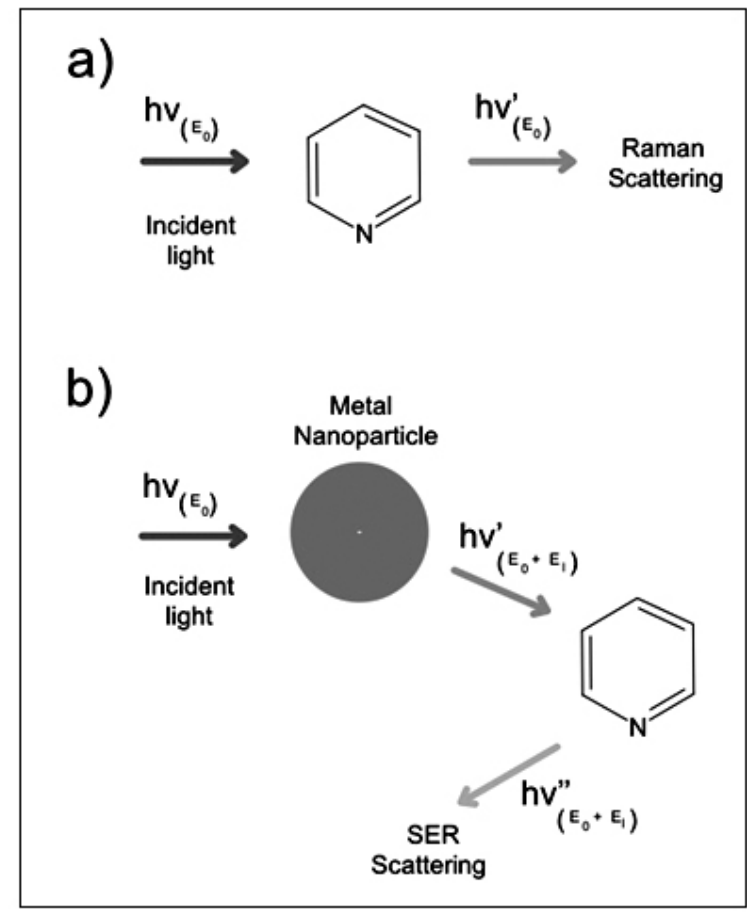

Scheme 1. a) Raman and b) SERS scattering schemes.

\section{Biomaterials.}

A biomaterial is defined in a review written by Bhullar et $\mathrm{al}^{32}$ as a "material that is adapted and used for a medical application". Historically, stones, ivory and a variety of polymers were used in China and Egypt as dental implants. Some uses of biomaterials were reported in the $16^{\text {th }}$ and $17^{\text {th }}$ centuries ${ }^{33}$. According to Web of Science about 11,000 articles were published from 2006 to 2017 in the field of science technology. 


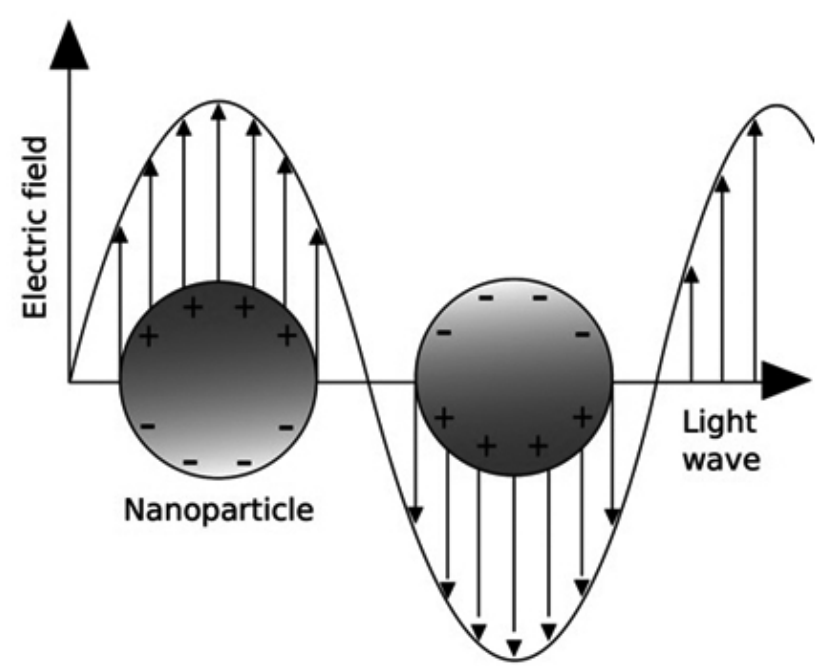

Scheme 2. Scheme of the excitation of the metallic nanoparticle and the electrons collective oscillation.

Biomaterials were developed for clinical applications. In this sense, the American National Institute of Health describes biomaterials as "any substance or combination of substances, other than drugs, synthetic or natural in origin, which can be used for any period of time, which augments or replaces partially or totally any tissue, organ or function of the body, in order to maintain or improve the quality of life of the individual". On the other hand, the Williams dictionary of biomaterials, define the term as "material intended to interface with biological systems to evaluate, treat, augment or replace any tissue, organ or function of the body" ${ }^{34}$. A comprehensive introduction and description about biomaterials is reviewed by Ratner ${ }^{35}$ and applications and materials are described by Tathe ${ }^{32}$. Furthermore, Patel et al ${ }^{36}$ reviewed the currently used biomaterials; metals, ceramics, polymers and composites from a chemical point of view; in this work, selected parameter for biomaterials such as biocompatibility, bio-functionality, toxicology, mechanical properties and others, are described. The authors point out that the success of a biomaterial or an implant is highly dependent on three major factors: properties of the biomaterials, biocompatibility of the implant and the health condition of the recipient. In the field of polymers, Ifkovits et al ${ }^{37}$ discuss on the biomaterial used in tissues engineering, the general aspects about the polymerization and degradation mechanism, and outline the various monomers and macromers that have been synthesized for the production of photopolymerizable and degradable biomaterials for applications in tissue regeneration. In an extended review by Bhullar et al ${ }^{38}$, authors explain that the smart biomaterials are designed to act as an "on-off" switch for various applications, which self-heals or responds to the changes (repeated for several times) in the environment when one of its property changes by the external conditions as temperature light, pressure, or electricity. These materials can deliver therapeutics to body designed sites. Some types of smart materials are piezoelectric, self-healing, thermoelectric, etc. The review emphasizes on biomedical applications of materials or structures that when expanded laterally are stretched or contracted in the transverse direction under uniaxial compression (auxetic materials), which come under the category of 16 smart materials of the twenty first century having a great impact in biomedical area. The most important aspect of a biomaterial is to display an adequate protein-surface interaction, and the Raman spectroscopy is a sensitive tool to study this interaction at this level, mainly due to their non-invasive and non-destructive analysis properties.

\section{Raman and SERS applications.}

3.1. Raman characterization of biomolecules and biomaterials.

Raman spectroscopy is used to study biomaterials in different biological aqueous environments such as tissue, blood and other body fluids. The Raman spectrum of water is very weak, much weaker than other solvents. The Raman signals of biomaterial-protein interactions in aqueous environments are measured at a wavelengths range closing to the visible or near IR. Under these conditions, the water absorption is minimal in comparison to the midIR wavelength range. This is the condition used to eliminate any signal contribution of water in the Raman spectrum.

In biomaterials, Raman spectroscopy is the main tool to study almost any chemical compound due to their no-sample preparation. A number of published studies have shown the use of Raman in the chemical structure identification of biomaterials ${ }^{39-46}$. For example, Wang et al ${ }^{39}$, used the band intensity in $\mathrm{I}(\mathrm{D}) / \mathrm{I}(\mathrm{G})$ ratio of the $\mathrm{G}$ band $\left(1558.93 \mathrm{~cm}^{-1}\right)$ and $\mathrm{D}$ band $\left(1354.63 \mathrm{~cm}^{-1}\right)$ to demonstrate the successful diamond-like carbon deposition on poly aryl-etherether-ketone, which was shown to improve the material properties for bone replacement applications. Other application of the Raman spectroscopy is related to the monitoring of surface modification procedures ${ }^{47}$. Applications of this technique includes contaminant analysis, polymer degradation assessments, identification of phases in polymer and pathological tissue sample analysis ${ }^{48}$. It has also been used to analyse the composition of bone and apatitic biomaterials ${ }^{49}$, image load-bearing surfaces in artificial hip joints ${ }^{50}$ and to monitor the effects of treatment protocols and subcutaneous implantation on bovine pericardium ${ }^{51}$. In other application, Raman spectroscopy was used to monitor and to optimize the time of the bone cement polymethyl methacrylate (PMMA) polymerization ${ }^{52}$.

In an extensive review, Lawson et al ${ }^{53}$ describe the uses of this technique in human applications, such as arteries, cancers and tumours, gallstones and kidney stones, hair and nails, teeth, implants and prostheses, foreign inclusions, eyes, cells, DNA, diagnosis of Alzheimer's disease and stratum cornea. In a work by Rehman ${ }^{54,55}$, Fourier transform-Raman spectroscopy (1064 nm) is used to identify the structural differences between human and sheep bones with implanted synthetic hydroxyapatite. From the spectral data analysis, it was possible to determinate that both types of bones have few common vibrational features.

Further, confocal Raman spectroscopy described by Harrington et al ${ }^{56}$, is related to in situ tensile testing to correlate changes in the secondary structure of proteins and supra-molecular structure of the whelk egg capsule (WEC) to mechanical properties in real time. The protein-based material that makes up the WEC was recently recognized because it presents a very remarkable mechanical behavior called pseudo-elasticity (sometimes called superelasticity). Complex biological materials, such as bone, silk or wood, often exhibit outstanding mechanical properties, a feature that is directly related to their functional adaptations and interactions at multiple hierarchical length scales. Raman spectroscopic imaging, a non-invasive and label-free approach to obtain both chemical (molecular interactions) and structural (orientation) information with sub-micrometer precision, is a powerful tool for the molecular level characterization of such materials ${ }^{56-60}$.

Raman imaging was employed by Gierlinger et al ${ }^{61}$ to investigate the spectral changes due to the orientation, as a basis to determine the microfibril orientation in single cells and cell wall layers. Thus, a fast laboratory method to investigate the microfibril angle (MFA) at the micron level, along with the chemical composition in the cell wall layers of different plant tissues were performed. The MFA of different cell types can be revealed, for example, in parenchyma, vessels and fibres in hard-woods or roots.

In Raman studies of collagen, Masic et al ${ }^{62}$ described the use of polarized Raman microspectroscopic and imaging analyses to elucidate the collagen fibril orientation at various levels of structure in native rat tail tendon under mechanical load. In situ humidity-controlled uniaxial tensile tests have concurrently been performed with Raman confocal microscopy to evaluate strain-induced chemical and structural changes of collagen in tendon. The methodology is based on the sensitivity of specific Raman scattering bands (associated with distinct molecular vibrations, such as the amide I mode) to the orientation and the polarization direction of the incident laser light. The results, based on the change in intensity of the Raman lines as a function of their orientation and polarization, support a model where the crimp and gap regions of collagen hierarchical structure are straightened at the tissue and molecular level, respectively. In this work, the lack of measurable changes in Raman peak positions throughout the whole range of strains investigated, indicates that no significant changes of the collagen backbone with tensing occurs, thus suggesting that the deformation is rather redistributed through other levels of the hierarchical structure.

The increasing number of works using Raman microspectroscopy to study biomaterials is due to that the Raman spectrometer is integrated with an optical microscope, allowing acquire spectral data from samples withou any additional invasive procedure. Penel et al ${ }^{49}$ used this technique to perform the microcharacterization of biomaterials in order to understand the pathophysiological events occurring in calcified tissues and synthetic biomaterials. The authors describe a new methodology to study the composition and structure of membranous bone in New Zeeland rabbits. The approach allows simultaneous observation of mineral and organic bone constituents providing insightful information. In the same way, Bennet et al ${ }^{63}$ studied the different mineral phases involved in bone formation of the zebrafish larvae (Danio rerio, 
fish emerged as a model organism to study vertebrate development) by using Confocal Raman microspectroscopy. The spectral results show the presence of hydrogen phosphate containing mineral phases in addition to the carbonated apatite mineral. Another use of the Raman microspectroscopy was reported by Rusciano et al ${ }^{63}$ to investigate the effect of polyhexamethylene biguanide at the single-cell level in Acanthamoeba keratitis a rare and serious disease. In this report, the authors concluded the great potential, rapid, cheap and effective diagnosis of Acanthamoeba keratitis by the analysis of DNA, proteins and lipids in cells by using Raman spectral data.

Raman microspectroscopy also allows two-dimensional (2-D) and threedimensional (3-D) imaging of a sample, providing a spatially resolved grid of spectra with location-specific fingerprinting of chemical bonds ${ }^{64}$. This complementary technique is considered as a high-resolution imaging tool in tissue engineering for in vivo studies. An example of the use of 3D imaging was discussed by Kallepitis et al ${ }^{65}$. In this report, the author exposes the use of Raman imaging and mapping of intracellular biomolecules. This new quantitative Raman imaging (qVRI) technique has the potential to investigate cell response and behavior in stem cell research, cancer biology and drug discovery. Authors demonstrate visualization and quantification of fine details in cell shape, cytoplasm, nucleus, lipid bodies and cytoskeletal structures in 3D with unprecedented biomolecular specificity for vibrational microspectroscopy.

\subsection{SERS characterization of biomolecules (amino acids, peptides and} proteins).

An important aspect in the study of biomaterials is the characterization of the chemical interactions between proteins within the biomaterial. A number of important studies have been published by different groups describing the interaction between amino acids, peptides and proteins with metal surfaces ${ }^{66-}$ ${ }^{68}$. The main aspect of these studies was to characterize the analytes by SERS, because these biomolecules are the first line to interact with the biomaterial. Extremely high enhancement levels occur for molecules attached to silver and gold nanoclusters. In two-photon excited Raman spectroscopy, strongly enhanced and highly confined local optical fields enable surface-enhanced Stokes and anti-Stokes Raman spectroscopy of single molecules, even under nonresonant excitation conditions as well as extremely large effective cross sections. The ability for very sensitive and spatially confined molecular structural probing makes gold and silver nanoclusters very promising tools for studies of small structures in biological materials, such as cellular compartments ${ }^{69}$. By SERS, the behavior and the orientation of the biomolecules on the surface were also studied. SERS experiments and quantum mechanical methods (mainly density functional theory, DFT) are used to infer about the adsorption of zwitterionic L-cysteine on silver surface via carboxylate, ammonium and sulphydryl groups ${ }^{68}$. The high specificity of this tool shows, for example, the trends of cysteine to form dipeptide in solution. In the case of L-tryptophan, a strong SERS spectrum resulted as consequence of the carboxylate and amino group surface interaction ${ }^{70}$. A stable orientation depending on the time settle as a unique spectral response was studied by Aliaga et al ${ }^{71}$. Other SERS studies involving theoretical data deals with amino acids such as L-lysine ${ }^{72}$, L-arginine ${ }^{73}$, and proline and hydroxyproline ${ }^{74}$. SERS experimental data combined with theoretical results obtained from molecular mechanics and Extended Hückel Theory (EHT) for the study of the interaction between the CLPFFD peptide and gold nanospheres, suggest that phenylalanine displays its aromatic ring coplanar to the surface ${ }^{67}$. This information has an important relationship with a previous work ${ }^{75}$ involving the role of electromagnetic irradiation on CLPFFD in Alzheimer's disease. The structure of the C-terminal peptide of pigeon cytochrome $\mathrm{C}\left(\mathrm{PCC}_{87-104}\right)$, a specific antigenic peptide used to study the immune response in vivo ${ }^{76-7-7}$, was deeply characterized. The authors aim was to develop a methodology to determine the influence that individual amino acids have on the interaction between the peptide and Ag metal surfaces. The net charge value and the hydrophilic characteristic of the $\mathrm{PCC}_{87-104}$ fragments were used to infer about the most probable sites of interaction with the metal surface. The negatively charged environment around the aspartic and glutamic acid moieties, suggests that this structural moiety takes place with the guanidinium group (in arginine) far from the nanoparticle surface. SERS shows a spectrum dominated by signals belonging to lysine and tyrosine. Theoretical data come up with the possible orientation of the peptide on the metal surface. Another study describes the interaction of the $\mathrm{C}$-terminal peptide from pigeon cytochrome $\mathrm{C}$ with silver nanoparticles ${ }^{79}$. A study using the peptide MRKDV (peptide motif of the hemocyanin extracted from Concholepas concholepas) shows its interaction with silver and a membrane surface ${ }^{80}$. The adsorption of the oligopeptides on silver nanoparticles was studied by Garrido et al ${ }^{81}$, where the influence of the amino acid sequence, hydrophobicity, charge of peptides and the relationship with the nanoparticles interface were determined using the peptides models ADEDRDA, LGRGISL and MRKDV supported by EHT and $6-31 \mathrm{G}^{*}$ calculations. In a related study, Wei et al ${ }^{66}$ performed experiments where the protein backbone contribution was used to understand dominant features in Raman and SERS spectra of the WC, YC, FC and CGGRQIKIWFQNRRMKWKK motifs. These data shed light on the behavior of proteins, peptides or amino acids in presence of surfaces. Previous studies suggest that the way to develop a new type of biomaterial should be supported by data from a metal-adsorbate SERS model ${ }^{82}$.

Moreover, Raman and SERS were employed in the study of human rotator cuff tissues after shockwave treatment ${ }^{83}$. Samples of type I and III of rat tail, bovine tail tissues, and human tendon tissue samples were used. The SERS information from 1016 SERS spectra of 52 biopsies of tendon tissues coated by AgNPs was used to understand the role of shockwaves employed in degenerated human tissue treatment. A comparison of the tissues indicates that the main observed differences between both tissue samples before and after the shockwave treatment were related to structural modifications in collagen, probably related to conformational aspects. The minimal spectral differences observed in the Raman spectra of collagen were ascribed to differences in the structural conformation.

A more complex study involved SERS experiments of the C-terminal peptide (37 amino acids) of the $\beta$-subunit human chorionic gonadotropin without linked carbohydrates; SERS and theoretical calculations were performed to determine the influence of the individual amino acids. In a sequence, the hydrophobicity and charge of the synthetic peptide, and the nanoparticles interface characteristics, drive the adsorption of the peptide on metal surfaces ${ }^{84}$. All of these studies have lead to the conclusion that the metal surface-peptide interactions are mainly governed by the nanoparticles surface charge and the local charge of each amino acidic component.

Metal surfaces can be functionalized to detect, for example, persistent organic pollutants. The functionalization of $\mathrm{AgNPs}$ by using different compounds such as bis-acridinium lucigenin ${ }^{85}$, humic acids ${ }^{86}$ and calixarenes ${ }^{87}$ was performed. The purpose of these studies was to obtain the SERS spectra of PAHs (polycyclic aromatic hydrocarbons) using those compounds as molecular assemblers.

The characterization of a 15 amino acid neurotransmitter called bombesin, was studied by Święch et al using SERS ${ }^{88}$. The authors used this technique to understand the changes in some amino acid geometry when the C-terminal fragment is adsorbed onto colloidal gold nanoparticles. Another peptide studied was the 9 amino acid inflammatory mediator, bradykinin. This compound was studied in the $\mathrm{pH}$ range 3-11 using gold colloidal nanoparticles (with 10, 20 and $50 \mathrm{~nm}$ diameter) ${ }^{89}$. The objectives of this work are focused on the interpretation of the specific interaction of peptides with nanoparticles; the orientation on the surface of the biomolecules depends on the $\mathrm{pH}$ condition ${ }^{90}$. These results indicate that the SERS methodology is a powerful approach to study these compounds.

Recent published results ${ }^{91}$ show the uses of another enhanced technique, the so called Surface-Enhanced Fluorescence (SEF), which is complementary with SERS to study the aggregation and detection of the anti-tumoral drug from the parietin lichens. Results indicated the variation of the SEF signal with the change in $\mathrm{pH}$ and the molecular organization on the surface. SERS spectra analysis allowed the identification of protonation and mono- and dideprotonation of parietin. Details about the conformation of the molecule on the silver surface were discussed by Lopez-Tobar ${ }^{91}$. The influence of $\mathrm{pH}$ on the SERS and SEF spectra is associated with processes such as ionization, tautomerization, aggregation and adsorption of this type of biomolecules onto the metal surface ${ }^{92}$. In a previous study by Lopez-Tobar et al ${ }^{93}$, the authors deal with the Raman and SERS characterization of the amyloid marker Thioflavin $\mathrm{T}(\mathrm{ThT})$ under different conditions (concentration and excitation lines) and environments. The aim of this approach is to be used for the in situ detection of amyloid fibrils, a protein disorder. Moreover, the analysis of the vibrational modes of ThT showed two different torsion angles of the molecule, which allows determine and differentiate the structure of molecules adsorbed on metal nanoparticles and in the multilayers surrounding the nanoparticles. Two structures of ThT were detected: (i) directly adsorbed onto the metal surface and (ii) molecules forming multilayers (similar to the structure of free ThT in aqueous solution) ${ }^{93}$

In a recent review, Cialla et al ${ }^{94}$, explain uses of SERS in the field of biomolecules and its approaches in the detection and characterization of nucleotides, nucleic acids, amino acids, peptides, proteins, phatogen sensing and cancer diagnosis. For example, some degradation products could be identified from biological fluids taking advantage of the SERS characterization of biomolecules such as biliverdin and bilirubin ${ }^{95}$. These bilichromes are included in the heme complex degradation and as part of some chromic 
diseases. Important features of SERS include: i) ultra high sensibility and ii) an important number of biomolecules characterization.

Recently, Pallaoro ${ }^{96}$ designed a SERS microfluidic channel device, based on a previously reported design, to identify and counts cancer cells using SERS biotag (a cancer-specific marker). In an important study by Maiti et a ${ }^{97}$, the authors deal with the use of SERS to detect breast cancer with SK-3 cells. SERS results exhibit the recognition of two different cancer cells with antibody-conjugated nanotags.

\section{Complementary techniques.}

SESORS (surface-enhanced spatially offset Raman spectroscopy) ${ }^{98}$, was developed and used for detection of a Raman reporter molecule through bone using nanotags. The SERS information was collected from a bone of 3 to $8 \mathrm{~mm}$ thickness, that is, the average thickness of the human skull. This technique has enormous potential as an in vivo spectroscopy approach and, in the future, as an imaging technique for studying neurochemicals in the brain.

Another recently developed technique, SHINERS (shell-isolated nanoparticles-enhanced Raman spectroscopy) ${ }^{99}$, is a tool with a promising future for the characterization and identification of isolated molecules. Only few articles have been published using this technique. SHINERS uses core@ shell nanoparticles with an inert isolated layer of $\mathrm{SiO}_{2} \mathrm{Al}_{2} \mathrm{O}$ or $\mathrm{MnO}_{2}$. Silver or gold nanospheres can be coated to prevent any reaction of the analytes with the nanoparticle surface. In this sense, it is possible to obtain an enhanced spectrum without the chemical mechanism contribution of the total enhancement (charge transfer complex). The main importance of isolated-nanoparticles resides in the possibility to obtain a dry nanomaterial to be used in future experiments.

Figure 1a shows the variation of the relative Raman intensity as a function of the thickness of the isolated-shell onto the nanoparticle. When its surface is naked, the SERS spectra have an important resolution with several bands. In the case of the compound $\mathrm{C} 3 \mathrm{AF}$, its aromatic and planar structure shows a fluorescent background in the whole spectrum. The relative intensity of the fluorescence in the SERS and SHINERS spectra becomes smaller as the distance between the molecule and the coated nanoparticle increases. A ful characterization using Raman, SERS, SHINERS and theoretical data was published ${ }^{100}$ for the sensor 1-(4-mercaptophenyl)-2,4,6-triphenylpyridinium perchlorate, a secondary betaine. The role of coated-nanoparticle is discussed and the electromagnetic contribution to the enhancement effect is concluded. Enhanced Raman signals obtained by using $\mathrm{Ag} @ \mathrm{SiO}_{2}$ nanoparticles resulted to be 5.1 times major relative to that obtained with naked Ag nanoparticles. An important use of SHINERS has been recently reported by Zheng, who explored the type II micro-calcifications in breast lesions ${ }^{101}$. It is important to mention the possibility to enhance the fluorescence using coated metallic nanoparticles. This technique is so called shell-isolated nanoparticles-enhanced fluorescence (SHINEF) ${ }^{102}$ a)

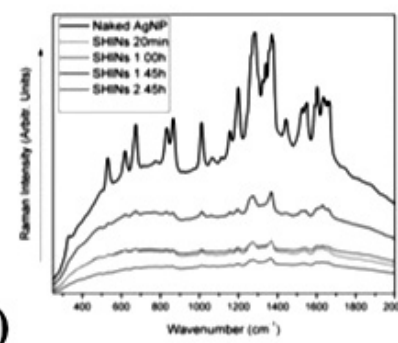

b)



c)

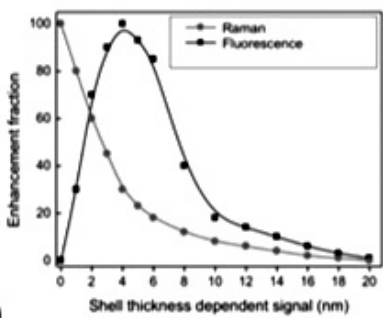

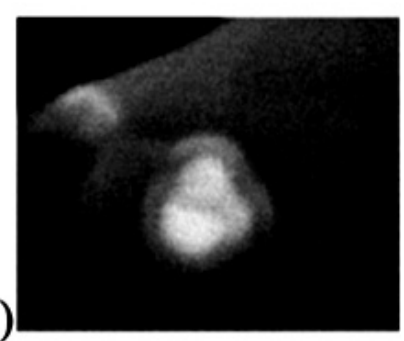

d)
In other cases, stable silver nanoparticles obtained by photo-reduction and coated with collagen were used as a potential anti-microbial agent 103. Experiments with AgNP@collagen showed bactericidal activity against Bacillus megaterium and E. coli, and bacteriostatic activity against staphylococcus epidermis without toxic effects on cells such as fibroblasts and keratinocytes. This type of biomaterial opens the opportunity to study the biological properties of nanoparticles from a SERS viewpoint. The same occurs in the work by Parnsamut ${ }^{104}$, where gold and silver nanoparticles were used in leukemic cells studies. The authors explain the roll of both nanoparticles inhibiting cell proliferation.

Kethani developed a tool with a prominent future named Hollow Core Photonic Crystal Fiber (HC-PCF) to monitor cells using SERS ${ }^{105}$. Mathematical results are treated using the partial least square (PLS) method, a quantitative analysis tool of multivariate analysis. Recent published works of HC-PCF by Kethani ${ }^{106,107}$ deals with the effect of volume and size of silver nanoparticles on SERS within HC-PCF and the potential use for monitoring leukemia cells using HC-PCF-SERS. The new technology can detect up to 300 cells $/ \mathrm{ml}$, which offers a number of important clinical uses.

An uncharted and highly desirable research area is the one relative to the excitation of SERS in the ultraviolet frequency to study many biological molecules, including protein residues and DNA bases. Metals such as $\mathrm{Pd}$ Pt ${ }^{108,109}$, Ru ${ }^{110,111}$, Rh ${ }^{109,111}$, Co ${ }^{111,112}$ and Al ${ }^{113}$ have been explored to find plasmonic properties in the UV region. The problem is the low enhancement factor $\left(\sim 10^{2}\right.$ order of magnitude) of these metals in the UV region. Only a few research groups have attempted to obtain UV SERS. For example, Dörfer et a ${ }^{113}$ explore the UV-SERS of crystal violet $10^{-4} \mathrm{M}$ on a $50 \mathrm{~nm}$ thick aluminium surface, while Ciu et al ${ }^{109}$ performed a systematic experimental investigation of charge-transfer enchancement of protonated adenine molecules adsorbed on $\mathrm{Rh}$ and Pd surfaces. The authors describe three kinds of enhancement mechanisms involved in the total effect: charge-transfer, electromagnetic field and preresonance Raman effect. This technique would be highly useful to investigate biological molecules, which have electronic resonances in this wavelength range, resulting in both electronic resonance and SERS enhancements.

SE-FSRS ${ }^{114}$ is composed by SERS and femtosecond stimulated Raman spectroscopy FSRS. The first one provides spectroscopic detection of single molecules, while the second one enables the Raman spectra acquisition in the ultrafast time scale of the molecular motion with simultaneous high time $(10-100 \mathrm{fs})$ and spectral $\left(5-20 \mathrm{~cm}^{-1}\right)$ resolution, thus tracking the structure of molecules as a function of time ${ }^{114,115}$. The first successful combination of these two techniques, demonstrate the SE-FSRS using gold nanoantennas with particular embedded molecules. FSRS has been used with hit to follow vibrational dynamics in a wide variety of systems, including proteins ${ }^{116-118}$ molecule-nanoparticle conjugates ${ }^{119}$, and small molecules ${ }^{120,121}$.

In the same way, Keller et al ${ }^{122}$ describes the Ultrafast SERS with pico and femtosecond time resolution. This technique has the ability to elucidate the mechanisms by which plasmons mediate chemical reactions. Here, the authors reviewed three important technological advances in these new methodologies SE-FSRS, surface-enhanced coherent anti-Stokes Raman spectroscopy (SECARS), and time-resolved SE-CARS (TR-SE-CARS). Also, the authors discuss their prospects for applications in areas including plasmon-induced chemistry and sensing at very low limits of detection.

\section{5.}

\section{CONCLUSION}

Raman and SERS, as well as other related spectroscopic techniques are decidedly useful to investigate structural changes when biomolecules interact with metal surfaces. The obtained information enables to a better understanding of the mechanisms related to the biomolecule/biomaterial interaction, thus allowing ensure a better chemical interaction. This is crucia to develop new biomaterials. The growing number of studies about SERS in the field of biomolecules reveals the importance of understanding the structural behavior of these molecules on biomaterials, the whole deposited on metal nanostructured surfaces. It is expected that the expansion of the reviewed spectroscopic techniques will rebound in instrumental advances, thus facilitating and increasing the investigation on the molecular structure of new materials.

\section{ACKNOWLEDGMENTS}

FC acknowledges to FONDECYT postdoctoral project 3150222. GDF thanks DGI Universidad de Playa Ancha for research time. MCV acknowledges project FONDECYT 1140524.
C AF $\left(1 \times 10^{-5} \mathrm{M}\right)$ b) Chemical structure of $\mathrm{C} 3 \mathrm{AF}$ c) Graph of dependenc fluorescence enhancement and Raman enhancement with the thickness of the shell onto the nanoparticle. d) SEM image of AgNP@ $\mathrm{SiO}_{2}$ 


\section{REFERENCES}

1.- $\quad$ Raman, C.; Krishnan, K. Nature 1928, 121 (3048), 501

2.- McCreery, R. Raman Spectroscopy for Chemical Analysis; Sons, J. W. \&, Ed.; New York, 2000.

3.- Jeanmaire, D. L.; Van Duyne, R. P. Van Duyne, R. P. J. Electroanal. Chem. 1977, 84, 1 .

4.- Fleischmann, M.; Hendra, P.; McQuillan, A. Chem. Phys. Lett. 1974, 26 (2), 2.

5.- Garrido, C.; Weiss-López, B. E.; Campos Vallette, M. M. Spectrosc. Lett. 2016, 49, 11 .

6.- Stamplecoskie, K. G.; Scaiano, J. C.; Tiwari, V. S.; Anis, H. J. Phys. Chem. C 2011, 115, 1403 .

7.- Garcia-Leis, A.; Garcia-Ramos, J. V.; Sanchez-Cortes, S. J. Phys. Chem. C 2013, 117 (15), 7791

8.- Leopold, N.; Lendl, B. J. Phys. Chem. B 2003, 107 (24), 5723.

9.- $\quad$ Turkevich, J.; Cooper, P.; Hillier, J. Discuss. Faraday Soc. 1951, 11 (c), 55.

10.- Lee, P. C.; Meisel, D. J.Phys.Chem. 1982, 86 (17), 3391.

11.- Alarcon, E. I.; Griffith, M.; Udekwu, K. Silver Nanoparticle Applications: In the fabrication and design of medical and biosensig devices; Alarcon, E. I., Griffith, M., Udekwu, K. I., Eds.; Engineering Materials; Springer International Publishing: Cham, 2015.

12.- Botta, O.; Bada, J.; Gomez-Elvira, J.; Javaux, E.; Selsis, F.; Summons, R. Strategies of life; Springer Science+Business Media: Pilbara, 2008; Vol. November.

13.- Wei, J.; Wang, A.; Lambert, J. L.; Wettergreen, D.; Cabrol, N.; WarrenRhodes, K.; Zacny, K. J. Raman Spectrosc. 2015, 46 (10), 810.

14.- Diaz Fleming, G.; Martinez-Ortiz, U.; Varas-Aquin, N. Int. J. Chem. Pharm. Sci. 2015, 3 (5), 1665.

15.- Diaz Fleming, G.; Martinez Ortiz, U. J. Spectrosc. Dyn. 2012, 2 (12), 1.

16.- Diaz Fleming, G.; Koch, R.; Muñoz Perez, J.; Llanos Cabrera, J. Vib. Spectrosc. 2015, 80, 70 .

17.- Diaz-Fleming, G.; Célis, F.; Fredes, C.; Campos-Vallette, M.; Aliaga, A. E.; Koch, R. J. Raman Spectrosc. 2010, 41 (2), 160.

18.- Cînta Pînzaru, S.; Pavel, I.; Leopold, N.; Kiefer, W. J. Raman Spectrosc. 2004, 35 (5), 338 .

19.- Diaz Fleming, G.; Célis, F.; Campos-Vallette, M.; Aliaga, A. E.; Escobar, M.; Koch, R. J. Raman Spectrosc. 2011, 42 (7), 1497.

20.- Pasteris, J. D.; Wopenka, B.; Freeman, J. J.; Brewer, P. G.; White, S. N.; Peltzer, E. T.; Malby, G. E. Appl. Spectrosc. 2004, 58 (7), 195A.

21.- Fleming, G. D.; Celis, F.; Aracena, A.; Campos-Vallette, M.; Aliaga, A. E.; Koch, R. Spectrochim. Acta-Part A Mol. Biomol. Spectrosc. 2012, $89,222$.

22.- Diaz Fleming, G.; Martinez, U.; Guerra, J. J. Spectrosc. Dyn. 2014, 4 (16), 1

23.- Diaz Fleming, G.; Villagrán, J.; Koch, R. Spectrochim. Acta Part A Mol. Biomol. Spectrosc. 2013, 114, 120

24.- Doty, K. C.; Muro, C. K.; Bueno, J.; Halámková, L.; Lednev, I. K. J. Raman Spectrosc. 2015, No. November 2015, 39

25.- Committee, A. M. Anal. Methods 2015, 7 (12), 4844.

26.- Chiao, M.; Chiao, J. Biomaterials for MEMS, 1st ed.; Chiao, M., Chiao, J. C., Eds.; Pan Stanford: Singapure, 2012; Vol. 33.

27.- Ducheyne, P. In Comprehensive Biomaterials II; Ducheyne, P., Grainger, D. B., Healy, K. E., Hutmacher, D. W., Kirkpatrick, C. J., Eds.; Elsevier: Oxford, 2017; p 2017

28.- Koburger, S.; Bannerman, A.; Grover, L. M.; Müller, F. A.; Bowen, J.; Paxton, J. Z. Biomater. Sci. 2014, 2 (1), 41

29.- Wu, Y.; Dong, Y.; Jiang, J.; Li, H.; Zhu, T.; Chen, S. Sci. Rep. 2017, 7 (12), 38706

30.- KUMAR, G. V. P. Bull. Mater. Sci. 2011, 34 (3), 417.

31.- Shashni, B.; Horiguchi, Y.; Kurosu, K.; Furusho, H.; Nagasaki, Y. Biomaterials 2017, 134, 143

32.- Tathe, A.; Ghodke, M.; Nikalje, A. P. Int. J. Pharm. Sci. 2010, 2 (4), 19.

33.- Misch, C. Contemporary implant dentistry; Mosby-Wolfe: London, 2007.

34.- Williams, D. F. Williams Dictionary of Biomaterials, 1st ed.; Liverpool University Press, 1999.

35.- Ratner, B.; Hoffman, A.; Schoen, F.; Lemons, J. Biomaterials science: An introduction to materials in medicine; Academic Press: Oxford, 2013.

36.- Patel, N. R.; Gohil, P. P. Int. J. Emerg. Technol. Adv. Eng. 2012, 2 (4), 91.

37.- Ifkovits, J. L.; Burdick, J. A. Tissue Eng. 2007, 13 (10), 2369

38.- Bhullar, S. K.; Lala, N. L.; Ramkrishna, S. Rev. Adv. Mater. Sci. 2015, 40 (3), 303 .
39.- Wang, H.; Xu, M.; Zhang, W.; Kwok, D. T. K.; Jiang, J.; Wu, Z.; Chu, P. K. Biomaterials 2010, 31 (32), 8181.

40.- Saber-Samandari, S.; Gross, K. A. Biomaterials 2010, 31 (25), 6386.

41.- Ku, S. H.; Park, C. B. Biomaterials 2010, 31 (36), 9431.

42.- Lopez-Heredia, M. A.; Sohier, J.; Gaillard, C.; Quillard, S.; Dorget, M.; Layrolle, P. Biomaterials 2008, 29 (17), 2608.

43.- Notingher, I.; Verrier, S.; Romanska, H.; Bishop, A. E.; Polak, J. M.; Hench, L. L. Spectroscopy 2002, 16 (2), 43.

44.- Notingher, I.; Hench, L. L. Expert Rev. Med. Devices 2006, 3 (2), 215.

45.- Bandyopadhyay, A.; Bose, S. Characterization of Biomaterials; Elsevier Inc.: Oxford, 2013.

46.- Hench, L. L.; Thompson, I. J. R. Soc. Interface 2010, 7 (May), S379.

47.- Born, R.; Scharnweber, D.; Rößler, S.; Stölzel, M.; Thieme, M.; Wolf, C. Worch, H. Fresenius. J. Anal. Chem. 1998, 361 (6-7), 697.

48.- Koening, J. Microscopic imaging of polymers; American Chemical Society: Washington, DC, 1998.

49.- Penel, G.; Delfosse, C.; Descamps, M.; Leroy, G. Bone 2005, 36 (5), 893

50.- Pezzotti, G. Anal. Bioanal. Chem. 2005, 381 (3), 577.

51.- Tarnowski, C. P.; Stewart, S.; Holder, K.; Campbell-Clark, L.; Thoma, R. J.; Adams, A. K.; Moore, M.; Morris, M. J. Biomed. Opt. 2003, 8 (2), 179

52.- Hagan, C. P.; Orr, J. F.; Mitchell, C. A.; Dunne, N. J. J. Mater. Sci. Mater Med. 2009, 20 (12), 2427.

53.- Lawson, E. E.; Barry, B. W.; Williams, A. C.; Edwards, H. G. M. J Raman Spectrosc. 1997, 28, 111

54.- Rehman, I.; Smith, R.; Hench, L. L.; Bonfield, W. J. Biomed. Mater. Res. 1995, 29, 1287.

55.- Smith, R.; Rehman, I. J. Mater. Sci. Mater. Med. 1994, 5 (9-10), 775.

56.- Harrington, M. J.; Wasko, S. S.; Masic, A.; Fischer, F. D.; Gupta, H. S.; Fratzl, P. J. R. Soc. Interface 2012, 9 (76), 2911.

57.- Schenk, A. S.; Zlotnikov, I.; Pokroy, B.; Gierlinger, N.; Masic, A.; Zaslansky, P.; Fitch, A. N.; Paris, O.; Metzger, T. H.; Cölfen, H.; Fratzl, P.; Aichmayer, B. Adv. Funct. Mater. 2012, 22 (22), 4668.

58.- Bratashov, D. N.; Masic, A.; Yashchenok, A. M.; Bedard, M. F. Inozemtseva, O. A.; Gorin, D. A.; Basova, T.; Sievers, T. K.; Sukhorukov, G. B.; Winterhalter, M.; Möhwald, H.; Skirtach, A. G. J. Raman Spectrosc. 2011, 42 (10), 1901.

59.- Lee, K.; Wagermaier, W.; Masic, A.; Kommareddy, K. P.; Bennet, M.; Manjubala, I.; Lee, S.; Park, S. B.; Cölfen, H.; Fratzl, P. Nat. Commun. 2012, 3, 725.

60.- Yashchenok, A.; Masic, A.; Gorin, D.; Shim, B. S.; Kotov, N. A.; Fratzl, P.; Möhwald, H.; Skirtach, A. Small 2013, 9 (3), 351.

61.- Gierlinger, N.; Luss, S.; Konig, C.; Konnerth, J.; Eder, M.; Fratzl, P. J. Exp. Bot. 2010, 61 (2), 587.

62.- Masic, A.; Bertinetti, L.; Schuetz, R.; Galvis, L.; Timofeeva, N.; Dunlop, J. W. C.; Seto, J.; Hartmann, M. A.; Fratzl, P. Biomacromolecules 2011, 12 (11), 3989.

63.- Bennet, M.; Akiva, A.; Faivre, D.; Malkinson, G.; Yaniv, K.; AbdelilahSeyfried, S.; Fratzl, P.; Masic, A. Simultaneous Raman Microspectroscopy and Fluorescence Imaging of Bone Mineralization in Living Zebrafish Larvae; Elsevier, 2014; Vol. 106.

64.- Narayan, R. J. Monitoring and Evaluation of Biomaterials and their Performance In Vivo; Narayan, R. J., Ed.; Elsevier Ltd: Kidlington, 2017.

65.- Kallepitis, C.; Bergholt, M. S.; Mazo, M. M.; Leonardo, V.; Skaalure, S. C.; Maynard, S. A.; Stevens, M. M. Nat. Commun. 2017, 8, 14843.

66.- Wei, F.; Zhang, D.; Halas, N. J.; Hartgerink, J. D. J. Phys. Chem. B 2008 $112(30), 9158$.

67.- Vera, A. M.; Cárcamo, J. J.; Aliaga, A. E.; Gómez-Jeria, J. S.; Kogan, M. J.; Campos-Vallette, M. M. Spectrochim. Acta Part A Mol. Biomol. Spectrosc. 2015, 134, 251.

68.- Diaz Fleming, G.; Finnerty, J. J.; Campos-Vallette, M.; Célis, F.; Aliaga, A. E.; Fredes, C.; Koch, R. J. Raman Spectrosc. 2009, 40 (6), 632

69.- Kneipp, K.; Kneipp, H.; Kneipp, J. Acc. Chem. Res. 2006, 39 (7), 443.

70.- Chuang, C.-H.; Chen, Y.-T. J. Raman Spectrosc. 2009, 40 (May 2008), 150 .

71.- Aliaga, A. E.; Osorio-Román, I.; Leyton, P.; Garrido, C.; Cárcamo, J.; Caniulef, C.; Celis, F.; Diaz F., G.; Clavijo, E.; Gómez-Jeria, J. S.; Campos-Vallette, M. M. J. Raman Spectrosc. 2009, 40 (2), 164.

72.- Aliaga, A.; Osorio-Roman, I.; Garrido, C.; Leyton, P.; Cárcamo, J.; Clavijo, E.; Gómez-Jeria, J. S.; Díaz, G.; Campos-Vallette, M. M. Vib. Spectrosc. 2009, 50 (1), 131

73.- Aliaga, A. E.; Garrido, C.; Leyton, P.; Diaz F., G.; Gomez-Jeria, J. S.; Aguayo, T.; Clavijo, E.; Campos-Vallette, M. M.; Sanchez-Cortes, S. Spectrochim. Acta - Part A Mol. Biomol. Spectrosc. 2010, 76 (5), 458. 
74.- Cárcamo, J. J.; Aliaga, A. E.; Clavijo, E.; Garrido, C.; Gómez-Jeria, J. S. Campos-Vallette, M. M. J. Raman Spectrosc. 2012, 43 (6), 750.

75.- Olmedo, I.; Araya, E.; Sanz, F.; Medina, E.; Arbiol, J.; Toledo, P.; Allvarez-Lueje, A.; Giralt, E.; Kogan, M. J. Bioconjug. Chem. 2008, 19 (6), 1154 .

76.- Carbone, F. R.; Fox, B. S.; Schwartz, R. H.; Paterson, Y. J. Immunol. 1987, $138(6), 1838$

77.- Bhayani, H.; Carbone, F. R.; Paterson, Y. J. Immunol. 1988, 141 (2), 377.

78.- Elgueta, R.; Tobar, J. a; Shoji, K. F.; De Calisto, J.; Kalergis, A. M. Bono, M. R.; Rosemblatt, M.; Sáez, J. C. J. Immunol. 2009, 183 (9), 277.

79.- Garrido, C.; Aliaga, A. E.; Gómez-Jeria, J. S.; Cárcamo, J. J.; Clavijo, E.; Campos-Vallette, M. M. Vib. Spectrosc. 2012, 61, 94.

80.- Aliaga, A. E.; Ahumada, H.; Sepúlveda, K.; Gomez-Jeria, J. S.; Garrido, C.; Weiss-López, B. E.; Campos-Vallette, M. M. J. Phys. Chem. C 2011 , $115(10), 3982$.

81.- Garrido, C.; Aliaga, A. E.; Gomez-Jeria, J. S.; Clavijo, R. E.; CamposVallette, M. M.; Sanchez-Cortes, S. J. Raman Spectrosc. 2010, 41 (10), 1149.

82.- Lal, S.; Grady, N. K.; Goodrich, G. P.; Halas, N. J. Nano Lett. 2006, 6 (10), 2338.

83.- Cárcamo, J. J.; Aliaga, A. E.; Clavijo, E.; Brañes, M.; Campos-Vallette M. M. J. Raman Spectrosc. 2012, 43 (2), 248

84.- Aliaga, A. E.; Aguayo, T.; Garrido, C.; Clavijo, E.; Hevia, E.; GómezJeria, J. S.; Leyton, P.; Campos-Vallette, M. M.; Sanchez-Cortes, S. Biopolymers 2011, 95 (2), 135.

85.- Guerrini, L.; Aliaga, A. E.; Cárcamo, J.; Gómez-Jeria, J. S.; SanchezCortes, S.; Campos-Vallette, M. M.; García-Ramos, J. V. Anal. Chim. Acta 2008, 624 (2), 286.

86.- Leyton, P.; Córdova, I.; Lizama-Vergara, P. A.; Gómez-Jeria, J. S.; Aliaga, A. E.; Campos-Vallette, M. M.; Clavijo, E.; García-Ramos, J. V.; Sánchez-Cortés, S. Vib. Spectrosc. 2008, 46 (2), 77.

87.- Leyton, P.; Domingo, C.; Sanchez-Cortes, S.; Campos-Vallette, M.; Garcia-Ramos, J. V. Langmuir 2005, 21 (25), 11814.

88.- Tąta, A.; Szkudlarek, A.; Kim, Y.; Proniewicz, E. Vib. Spectrosc. 2016, 84,1

89.- Święch, D.; Kim, Y.; Proniewicz, E. Vib. Spectrosc. 2016, 83, 101

90.- Domin, H.; Pieta, E.; Piergies, N.; Swiech, D.; Kim, Y.; Proniewicz, L. M.; Proniewicz, E. J. Colloid Interface Sci. 2015, 437, 111.

91.- Lopez-Tobar, E.; Verebova, V.; Blascakova, L.; Jancura, D.; Fabriciova, G.; Sanchez-Cortes, S. Spectrochim. Acta Part A Mol. Biomol. Spectrosc. 2016, 159,134

92.- Lajos, G.; Jancura, D.; Miskovsky, P.; García-Ramos, J. V.; SanchezCortes, S. J. Phys. Chem. C 2008, 112 (33), 12974.

93.- Lopez-Tobar, E.; Antalik, M.; Jancura, D.; Vega, M.; Garc, A.; Fedunova, D.; Fabriciova, G.; Sanchez-Cortes, S. J. Phys. Chem. C 2013, 117, 3996.

94.- Cialla, D.; Pollok, S.; Steinbrücker, C.; Weber, K.; Popp, J. Nanophotonics 2014, 3 (6), 383.

95.- Celis, F.; Campos-Vallette, M. M.; Gómez-Jeria, J. S.; Clavijo, R. E.; Jara, G. P.; Garrido, C. Spectrosc. Lett. 2016, 49 (5), 336.

96.- Pallaoro, A.; Hoonejani, M. R.; Braun, G. B.; Meinhart, C. D.; Moskovits, M. ACS Nano 2015, 4 (4), 4328.

97.- Maiti, K. K.; Samanta, A.; Vendrell, M.; Soh, K.-S.; Olivo, M.; Chang, Y.-T. Chem. Commun. 2011, 47 (12), 3514

98.- Sharma, B.; Ma, K.; Glucksberg, M. R.; Van Duyne, R. P. J. Am. Chem Soc. 2013, 135 (46), 17290.

99.- Li, J. F.; Huang, Y. F.; Ding, Y.; Yang, Z. L.; Li, S. B.; Zhou, X. S.; Fan, F. R.; Zhang, W.; Zhou, Z. Y.; Wu, D. Y.; Ren, B.; Wang, Z. L.; Tian, Z Q. Nature 2010, 464 (7287), 392

100.-Celis, F.; Campos-Vallette, M.; Cárcamo, J.; Gómez-Jeria, J.; Aliaga, C. J. Chil. Chem. Soc. 2015, 60 (2), 2944.

101.-Zheng, C.; Shao, W.; Paidi, S. K.; Han, B.; Fu, T.; Wu, D.; Bi, L.; Xu, W.; Fan, Z.; Barman, I. Nanoscale 2015, 7 (40), 16960.

102.-Guerrero, A. R.; Aroca, R. F. Angew. Chemie Int. Ed. 2011, 50 (3), 665

103.-Alarcon, E. I.; Udekwu, K.; Skog, M.; Pacioni, N. L.; Stamplecoskie, K. G.; González-Béjar, M.; Polisetti, N.; Wickham, A.; Richter-Dahlfors, A.; Griffith, M.; Scaiano, J. C. Biomaterials 2012, 33 (19), 4947.

104.-Parnsamut, C.; Brimson, S. Genet. Mol. Res. 2015, 14 (2), 3650

105.-Khetani, A.; Riordon, J.; Tiwari, V.; Momenpour, A.; Godin, M.; Anis, H. Opt. Express 2013, 21 (10), 12340.

106.-Khetani, A.; Momenpour, A.; Alarcon, E. I.; Anis, H. Biomed. Opt. Express 2015, 23 (22), 8992.

107.-Tiwari, V. S.; Khetani, A.; Momenpour, A.; Anis, H. IEEE J. Sel. Top Quantum Electron. 2014, 20 (3), 1.
108.-Cui, L; Mahajan, S.; Cole, R. M.; Soares, B; Bartlett, P. N.; Baumberg, J. J.; Hayward, I. P.; Ren, B.; Russell, a E.; Tian, Z. Q. Phys. Chem. Chem. Phys. 2009, 11 (7), 1023.

109.-Cui, L.; Wu, D.; Wang, A.; Ren, B.; Tian, Z. J. Phys. Chem. C 2010, 114 (39), 16588

110.-Ren, B.; Lin, X.-F.; Yang, Z.-L.; Liu, G.-K.; Aroca, R. F.; Mao, B.-W.; Tian, Z.-Q. J. Am. Chem. Soc. 2003, 125 (32), 9598.

111.-Lin, X.-F.; Ren, B.; Yang, Z.-L.; Liu, G.-K.; Tian, Z.-Q. J. Raman Spectrosc. 2005, 36 (6-7), 606.

112.-Tian, Z.-Q.; Yang, Z.-L.; Ren, B.; Wu, D.-Y. In Surface-Enhanced Raman Scattering: Physics and Applications; Kneipp, K., Moskovits, M., Kneipp, H., Eds.; Springer Berlin Heidelberg: Berlin, Heidelberg, 2006; pp 125-146.

113.-Dörfer, T.; Schmitt, M.; Popp, J. J. Raman Spectrosc. 2007, 38 (11) 1379.

114.-Frontiera, R. R.; Henry, A.-I.; Gruenke, N. L.; Van Duyne, R. P. J. Phys. Chem. Lett. 2011, 2 (10), 1199.

115.-Kukura, P.; McCamant, D. W.; Mathies, R. A. Annu. Rev. Phys. Chem. 2007, 58 (1), 461.

116.-Kukura, P.; McCamant, D. W.; Yoon, S.; Wandschneider, D. B.; Mathies, R. A. Science (80-. ). 2005, 310 (5750), 1006

117.-Fang, C.; Frontiera, R. R.; Tran, R.; Mathies, R. A. Nature 2009, 462 (7270), 200.

118.-Dasgupta, J.; Frontiera, R. R.; Taylor, K. C.; Lagarias, J. C.; Mathies, R. A. Proc. Natl. Acad. Sci. 2009, 106 (6), 1784.

119.-Frontiera, R. R.; Dasgupta, J.; Mathies, R. A. J. Am. Chem. Soc. 2009 131 (43), 15630.

120.-Laimgruber, S.; Schreier, W. J.; Schrader, T.; Koller, F.; Zinth, W.; Gilch P. Angew. Chemie Int. Ed. 2005, 44 (48), 7901.

121.-Lockard, J. V.; Butler Ricks, A.; Co, D. T.; Wasielewski, M. R. J. Phys. Chem. Lett. 2010, 1 (1), 215.

122.-Keller, E. L.; Brandt, N. C.; Cassabaum, A. A.; Frontiera, R. R. Analyst 2015, 140 (15), 4922. 